Levine, E. E., Roberts, A. R., \& Cohen, T. R. (in press 2019). Difficult conversations: Navigating the tension between honesty and benevolence. Current Opinion in Psychology [To be published in special issue on Privacy and Disclosure, Online and in Social Interactions].

\author{
Difficult Conversations: \\ Navigating the Tension between Honesty and Benevolence \\ Emma E. Levine ${ }^{\mathrm{a}}$, Annabelle R. Roberts ${ }^{\mathrm{a}}, \&$ Taya R. Cohen ${ }^{\mathrm{b}}$ \\ ${ }^{a}$ University of Chicago, Booth School of Business \\ ${ }^{\mathrm{b}}$ Carnegie Mellon University, Tepper School of Business
}

We are grateful for feedback and advice from Nicholas Epley, George Wu, and Xuan Zhao. Address correspondence to Emma Levine, The University of Chicago Booth School of Business, 5807 S Woodlawn Ave, Chicago, IL 60637. Email: Emma.Levine@chicagobooth.edu, Phone: 773-834-2861. 


\begin{abstract}
Difficult conversations are a necessary part of everyday life. To help children, employees, and partners learn and improve, parents, managers, and significant others are frequently tasked with the unpleasant job of delivering negative news and critical feedback. Despite the long-term benefits of these conversations, communicators approach them with trepidation, in part, because they perceive them as involving intractable moral conflict between being honest and being kind. In this article, we review recent research on egocentrism, ethics, and communication to explain why communicators overestimate the degree to which honesty and benevolence conflict during difficult conversations, document the conversational missteps people make as a result of this erred perception, and propose more effective conversational strategies that honor the long-term compatibility of honesty and benevolence. This review sheds light on the psychology of moral tradeoffs in conversation, and provides practical advice on how to deliver unpleasant information in ways that improve recipients' welfare.
\end{abstract}

Abstract word count: 150

Current manuscript word count: 


\section{Difficult Conversations: \\ Navigating the Tension between Honesty and Benevolence}

Difficult conversations - conversations in which the provision of true information may cause discomfort to the communicator or the target - are ubiquitous in everyday life. To effectively manage employees, teach students, raise children, and build intimate relationships, we are often taxed with the unpleasant task of delivering negative news or critical feedback. Consider a professor working closely with a doctoral student, who despite his intelligence and motivation, fails to make progress on his research. The professor comes to believe that the student will not succeed in academia, which is information that the professor believes would devastate the student. The professor calls a meeting to discuss the student's future, but as the meeting gets closer, she grows increasingly anxious about communicating honestly with the student. How can the professor share what she believes to be truthful, useful feedback while also being a kind and supportive mentor and confidante?

Navigating this conversation is difficult because the communicator must wrestle with two moral motivations that they may perceive to conflict: the motivation to be honest and the motivation to be kind $\left[19^{* *}\right]$. People are motivated to maintain the belief that they are moral $[3$, 31]. In conversations that involve potential tradeoffs between honesty and kindness, optimizing on both dimensions is likely to be quite difficult. In the present research, we present new insights on the psychology of difficult conversations by analyzing them through the lens of ethical dilemmas. We integrate research on egocentrism, moral judgment, and communication to highlight why communicators systematically mismanage difficult conversations, and provide practical advice on how these conversations could be improved.

\section{The honesty-benevolence dilemma in difficult conversations}


Delivering negative information is often regarded as a necessary evil [28, 29]: It requires harming someone in the short-term in order to provide long-term benefits. Consider the graduate student in the opening example. Honest critical feedback is likely to hurt the student's feelings in the short-term (perhaps quite severely), but it serves a broader long-term goal: Honest feedback can help the student improve, and if necessary, find a career that will better suit his skills. During other difficult conversations, honesty may be associated with immediate social harms such as shame or anger, and long-term benefits such as increasing trust [45], intimacy [18], and motivation [8].

Notably, communicators will come to very different conclusions about the benefits of difficult conversations based on whether they focus on these short-term versus long-term consequences. If a communicator only considers the immediate impact of their words, they are likely to conclude that honesty and benevolence are fundamentally at odds. However, if a communicator considers the long-term consequences of their words, they are more likely to recognize that honesty and benevolence are actually compatible.

Our view is that communicators should, but often do not, take a long-term perspective. We define benevolence as the motivation to improve the welfare of a specific individual in need $[30,32]$. Therefore, a person who is truly benevolent towards a target should be willing to enact some amount of emotional harm if it meaningfully promotes the target's overall welfare. Indeed, the core tenet of utilitarianism - a common normative framework for resolving ethical dilemmas - is that people should be willing to enact instrumental harm if it promotes social welfare [12].

\section{Why communicators make mistakes when faced with the honesty-benevolence dilemma}

Why do communicators often fail to act benevolently when engaging in difficult conversations? There are (at least) two processes that can lead communicators to err in their 
assessments of how difficult conversations affect a target's welfare. First, communicators overestimate the magnitude of harm caused by difficult conversations. Second, they attend more to the short-term harm than the long-term benefits of difficult conversations.

A "focusing illusion" could lead communicators to overestimate the degree to which difficult conversations harm targets $[9,25,44]$. People tend to focus on easily observable information, such as the content of the conversation, rather than the broader context of the information, such as the communicator's intent or relationship with the target. However, when there is reason for the target to believe that the communicator has good intentions (e.g., if they are friends or if the communicator explicitly states their benevolent intentions) then the target is unlikely to be dramatically harmed $\left[7^{*}, 45\right]$. Indeed, targets are more attentive to communicators' intentions and overall warmth than communicators expect [17*, 48]. This leads communicators to overestimate how negatively their close relational partners will react to critical feedback. Communicators significantly overestimate how painful honest conversations will be and underestimate how beneficial they will be for their social relationships. Evidence of this comes from an experiment we conducted, which showed that participants who were assigned to focus on being honest in every conversation with every person in their life for three days found the experience to be more pleasurable, meaningful, socially connecting, and less harmful for their relationships relative to the predictions they made before engaging in the experience, and relative to the predictions of outside observers [20**].

Even when communicators accurately predict the harm caused by difficult conversations, they may over-attend to it, relative to the conversation's potential long-term benefits. This can occur for a variety of reasons. First, the long-term benefits may simply be less available because they are not directly experienced [40]. Communicators directly experience the difficult 
conversation and its immediate consequences (while they choose their words and witness a target's reaction) but are left to imagine how the conversation affects the target in the long-term. This might lead communicators to feel more uncertain about the benefits of difficult conversations and therefore avoid engaging in them [10]. The asymmetric timing of the costs and benefits of difficult conversations may also lead to overweighting of the immediate costs, relative to the long-term benefits, given people's general tendency to be present-biased [33]. Finally, communicators experience a personal cost when they enact harm [4], but do not necessarily experience personal benefits when a target improves in the future. People tend to be more attentive to how behaviors affect themselves than other people $[6,46]$, which can lead to abundant social errors in both written [16] and verbal communication [2*, 41, 42*].

\section{Suboptimal, but common strategies for dealing with the honesty-benevolence dilemma}

Because communicators overestimate and over-attend to the short-term harm of difficult conversations, they often choose strategies that are intended to resolve the short-term conflict between honesty and harm, but ultimately do not promote the welfare of their conversational partners. This can take many forms. Communicators might: 1) avoid difficult conversations altogether, 2) prioritize honesty over benevolence or vice versa, and/or 3) communicate in a way that is neither honest nor benevolent. Suboptimal decisions about how to communicate can result from deliberate, intentional thought processes, non-conscious, automatic thought processes, or some combination of intentional and automatic thought processes that unfold throughout the conversation. Regardless of how suboptimal communication decisions come about, what they share in common is that they fail to fully maximize honesty and benevolence, and instead prioritize one value over the other, or compromise on both. Figure 1 outlines these potential 
strategies for dealing with the tension between honesty and benevolence in difficult conversations.

Figure 1. Strategies for Navigating Difficult Conversations

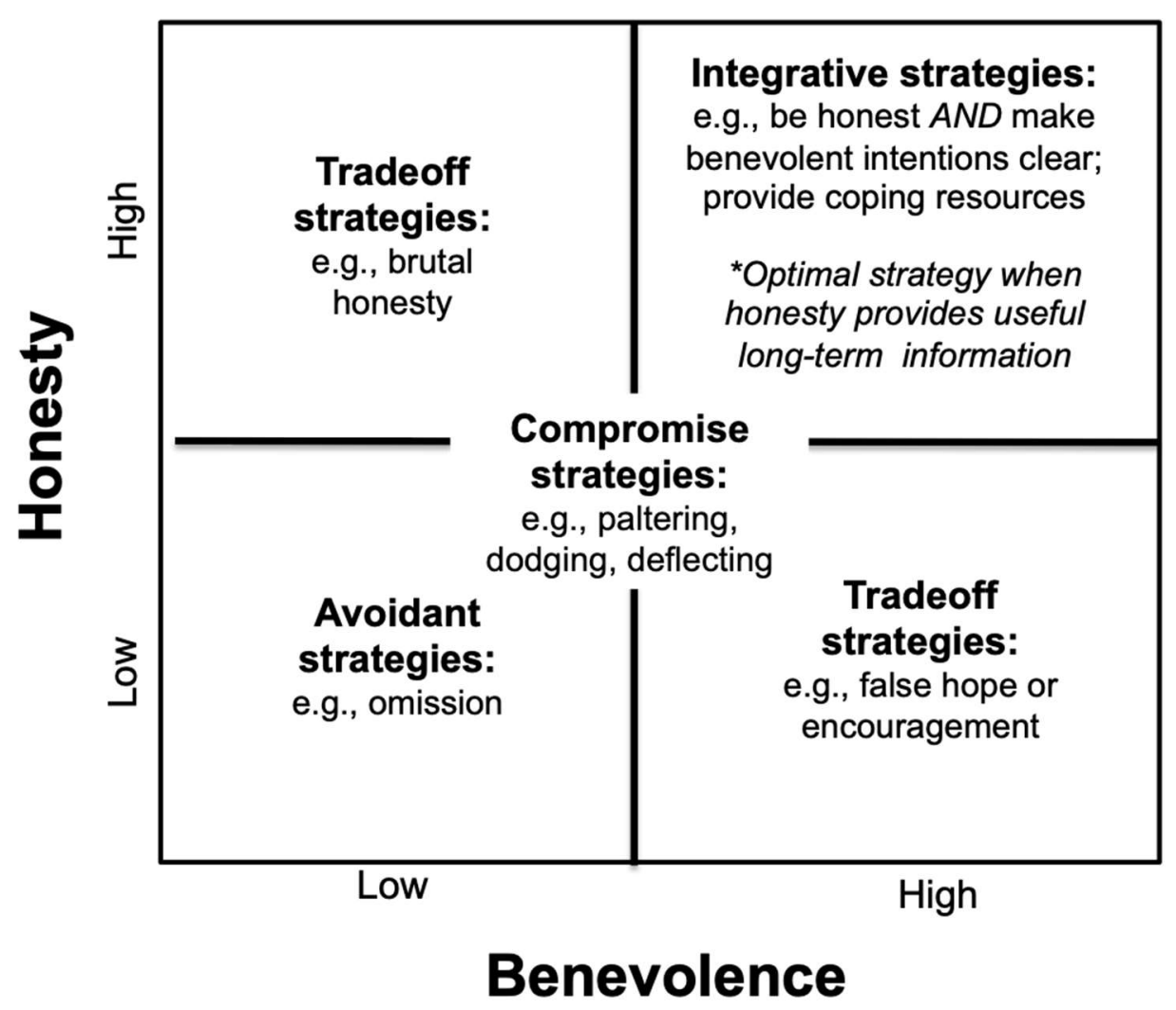

\subsection{Avoidance}

Perhaps the easiest way to avoid making a mistake in an ethical dilemma is to avoid the dilemma altogether $[5,35,36]$. Indeed, many communicators resolve the tension between honesty and benevolence by avoiding difficult conversations entirely [39, 43] or by omitting information $[23 * *]$. Communicators may regard this as an appealing strategy because it allows them to feel that they have not actively done anything wrong. By not discussing sensitive information, a communicator can maintain the belief that they have been honest (or that they have at least avoided being dishonest) and that they have not caused harm. 
However, this strategy is problematic because it can cause harm. Omission prevents targets from learning important information that could benefit targets in the long-term. Recent studies demonstrate that targets recognize this and penalize communicators accordingly. For example, an experiment by Levine and colleagues [23**] found that within an economic game, targets shared less money with communicators who had refused to provide information to them, compared to communicators who had told lies that benefited them. Communicators fail to anticipate the costs of omission because omission feels justifiable to them - they anticipate feeling less guilty if they omit information than if they actively lie, leading communicators to engage in omission quite frequently. This influences communication in economic games and in high-stakes difficult conversations. Levine and colleagues also found that practicing oncologists believe that it is more acceptable to lie by omission (e.g., fail to provide negative prognostic information when the patient has falsely positive beliefs) than to actively provide patients with false hope, and report being more likely to engage in lies of omission. However, actual cancer patients believe the opposite: they believe it is more acceptable and are more desiring of false hope than lies of omission [23**].

Avoidance strategies, though easily justified by communicators, are often the least effective at promoting targets' welfare. Omission fails to deliver the informational benefits of honesty, and by reducing communication between communicators and targets, fails to deliver the emotional benefits of sensitive communication (e.g., hope, comfort, intimacy). Avoidance is also problematic because it robs communicators of valuable feedback on how targets react to difficult conversations, feedback which might lead communicators to make less biased judgments of the benefits of these conversations moving forward [19].

\subsection{Prioritizing honesty or benevolence}


When communicators do engage in difficult conversations, the experience of moral conflict may lead them to simply prioritize one value over the other. Ethical dilemmas tax cognitive resources [29] and narrow decision-makers' thinking [15*]. Moral choices create a powerful sense of psychological constraint that leads decision-makers to feel less choice even when they have multiple options available to them $\left[15^{*}\right]$. When decision makers become fixated on the choices in front of them, it reduces their ability to come up with creative solutions to ethical problems [47**]. For example, in Kohlberg's classic Heinz dilemma [14] people are faced with a choice between stealing a drug that their spouse needs for survival (displaying loyalty and avoiding harm) and obeying laws that protect property (acting fairly). In this dilemma, people typically just choose one of these options, failing to recognize that creative solutions are possible that integrate both motives (e.g., asking the scientist who owns the medicine if they can have the drug for a reduced price) [47**].

In the context of difficult conversations, tradeoff strategies entail choosing either honesty or benevolence. For instance, in the opening example, this might take the form of brutal truth telling with no buffering (e.g., "You are not cut out for academia, period."), or prosocial lying (lying to benefit another person, e.g., "You are doing fine, just keep trying") [21, 26**]. The former would reflect trading off benevolence for honesty, whereas the latter would reflect trading off honesty for short-term benevolence. Both of these strategies can be problematic. Without benevolence, the motivation for honesty is likely to be questioned [21, 22]. Within a single interaction, it is not clear if the professor's behavior is motivated by a rule of honesty or callous disregard for the student's feelings [32]. Therefore, the student is likely to distance himself from the communicator, and can easily misconstrue the feedback as petty criticism or a personal attack rather than an attempt to help. Prosocial lying, on the other hand, often sacrifices the overall 
welfare of the target and can lead to unrealistic expectations and unjustified hope for the future. Furthermore, if prosocial lies are detected by a target, they can be perceived as paternalistic and offensive, and could lead to resentment towards the communicator. [27*]. Notably, however, prosocial lies do not sacrifice long-term benevolence, nor do they yield resentment, when honesty causes unnecessary harm [24]. We return to this idea in the conclusion of our paper.

\subsection{Compromise strategies: Paltering, dodging, and deflecting}

Many ethical dilemmas - especially those studied by ethics scholars (e.g., the trolley problem [11]) - force actors to choose between two discrete outcomes. Conversational dilemmas are different in that they also allow actors to honor moral values to varying degrees.

Communicators need not choose between complete honesty and complete deception; they have a whole host of conversational strategies available to them that lie between these two choices. Accordingly, communicators frequently resolve the perceived honesty-benevolence tradeoff in difficult conversations via compromise solutions.

For example, the professor in the opening example might tell her student a truthful statement, such as "You are doing a great job with your classes," which is honest and has the benefit of making the student feel good. However, in the absence of more information, this statement will likely mislead the student into believing that he is doing well and on track for success, despite the fact that classwork is a relatively weak indicator of potential for success in academia. In other words, though this palter (i.e., a statement that is true, but told with the intention of misleading someone) feels more ethical than an outright lie to the communicator, it has the same consequences as an outright lie to the target [ $\left.38^{* *}\right]$.

Communicators make significant distinctions between the ethicality of outright lies and compromising tactics such as palters, but targets do not [38**]. For example, communicators 
think that providing truthful but misleading information in a negotiation is more ethical than directly lying, while targets view the two statements as morally equivalent [ $\left.38^{* *}\right]$. Other compromising strategies such as dodging [37] or deflecting [1] questions are likely to be perceived similarly to paltering. Though easily justified by communicators, these communication tactics compromise both honesty and benevolence. Unlike, avoidance strategies, they do not involve omitting information altogether, but compromise strategies nonetheless still fail to deliver accurate information to the target that could improve the target's long-term welfare.

\section{A better approach: Maximizing honesty and benevolence}

Communicators predominantly focus on choosing the "right" words (including no words at all) to balance honesty and benevolence in the short-run. We suggest that this is the wrong approach because it typically leaves the target with an inaccurate impression of the truth (either because the communicator fails to provide full information or the target discounts the communicator's words) and frequently fails to convey benevolence despite the communicator's goals to do just that. Communicators must look beyond the short-term conflict between honesty and emotional harm to promote the welfare of their conversational partners. However as reviewed above, ignoring the short-term harm of difficult truths by being brutally honest is also ineffective.

We propose that a better approach is for communicators to focus on delivering negative information truthfully and directly, but also employ additional strategies to ensure that their words actually lead to long-term improvement. In other words, communicators must integrate honesty and benevolence in an attempt to maximize both dimensions, rather than prioritizing one moral value at the expense of the other or compromising on both. This framework for navigating the challenges of difficult conversations mirrors the dual concerns model from the conflict and 
negotiations literature [34], which similarly suggests that an optimal approach to navigating the tension between concerns for one's self and one's counterpart is to simultaneously maximize on both dimensions rather than trading off one at the expense of the other, compromising on both, or avoiding the dilemma altogether.

While communicating in a way that optimizes both honesty and benevolence may not be easy, we contend that it is indeed possible. One way communicators can do this is to clearly state their benevolent intentions before delivering candid feedback [45]. For example, a professor might emphasize that a student is capable of achieving high standards when giving critical feedback (e.g., 'I’m giving you these comments because I have very high expectations and I know you can reach them" [45]). Though this strategy may seem intuitive, communicators often fail to make their benevolent intentions clear-they seem to forget (at least in the moment) that targets do not have access to this information [13].

A second strategy is to provide targets with the resources necessary to either cope with or learn from the information [29]. For example, doctors might devote time to checking back in with a patient to provide emotional support after having presented them with unpleasant information about their prognosis; and, police officers might instruct evictees about the law and how to navigate it in order to help tenants protect themselves in the future [29]. The professor in the opening example might suggest specific resources to help the student and offer to meet more frequently with him to help him improve. These strategies honor the long-term compatibility of honesty and benevolence by providing the target with information, reducing the likelihood that the target discounts honesty as cruel criticism, and ensuring that the information leads to the desired outcome of improved welfare.

\section{Summary and an important caveat}


Difficult conversations that require the delivery of negative information from communicators to targets involve perceived moral conflict between honesty and benevolence. We suggest that communicators exaggerate this conflict. By focusing on the short-term harm and unpleasantness associated with difficult conversations, communicators fail to realize that honesty and benevolence are actually compatible in many cases. Providing honest feedback can help a target to learn and grow, thereby improving the target's overall welfare. Rather than attempting to resolve the honesty-benevolence dilemma via communication strategies that focus narrowly on the short-term conflict between honesty and emotional harm, we recommend that communicators instead invoke communication strategies that integrate and maximize both honesty and benevolence to ensure that difficult conversations lead to long-term welfare improvements for targets. Future research should explore the traits, mindsets, and contexts that might facilitate this approach. For example, creative people may be more adept at integrative solutions to the perceived honesty-dilemma conflict, and people who are less myopic and more cognizant of the future consequences of their choices may be better at recognizing the long-term benefits of honesty.

An important caveat to our recommendations are that they only apply to situations in which honest feedback is indeed helpful to targets in the long-term (e.g., conversations that involve negative feedback that is ultimately useful for the target to know). Notably, not all truths improve a target's welfare, and in fact, some truths yield what many would call "unnecessary harm" [24] For example, providing negative feedback on things a target cannot control or improve upon hurts the targets feelings, without leading to any long-term benefit, thus causing unnecessary harm $[21,22,24])$. In other words, there are indeed situations in which honesty and benevolence do fundamentally conflict, and in which tradeoffs are essential. In these situations, 
targets appreciate prosocial lies. Interestingly, egocentrism may produce a similar (but seemingly opposite error) in which communicators underestimate the value of prosocial lying [23**] in these cases. Nonetheless, in order to identify optimal strategies within conversations involving moral conflict, communicators must refocus their attention on the long-term, rather than shortterm, consequences of honesty and benevolence. Failing to consider the future impact of one's communication runs the risk of making everyone worse off. 


\section{References and recommended reading}

* of special interest

** of outstanding interest

1. Bitterly TB, Schweitzer M: The Economic and Interpersonal Consequences of Deflecting Direct Questions. Unpublished results.

2.* Boothby EJ, Cooney G, Sandstrom GM, Clark MS: The liking gap in conversations: do people like us more than we think?. Psychological science. 2018, 11:1742-56.

An empirical article that demonstrates people systematically underestimate the extent to which their conversation partners liked interacting with them (i.e. the liking gap).

3. Cohn, A, Cohn, A, Maréchal, MA, Tannenbaum, D, \& Zünd, CL: Civic honesty around the globe. Science. 2019, 8712(June): 1-9.

4. Cushman F, Gray K, Gaffey A, Mendes WB: Simulating murder: The aversion to harmful action. Emotion. 2012, 1:2-7.

5. Dana J, Cain DM, Dawes RM: What you don't know won't hurt me: Costly (but quiet) exit in dictator games. Organizational Behavior and human decision Processes. 2006, 2:193-201.

6. Epley N, Keysar B, Van Boven L, Gilovich T: Perspective taking as egocentric anchoring and adjustment. Journal of personality and social psychology. 2004, 3: 32739.

7.* Finkelstein SR, Fishbach A, Tu Y: When friends exchange negative feedback. Motivation and Emotion, 2017, 41:69-83.

An empirical article that finds actual and perceived relationship depth increases the amount of negative feedback people seek from and provide to each other.

8. Fishbach A, Eyal T, Finkelstein SR: How positive and negative feedback motivate goal pursuit. Social and Personality Psychology Compass, 2010, 8:517-30.

9. Gilbert DT, Wilson TD: Miswanting: Some problems in forecasting of future affective states. In Studies in emotion and social interaction, second series. Feeling and thinking: The role of affect in social cognition. Edited by Forgas JP. Cambridge University Press; 2000:178-97.

10. Gneezy U, List JA, Wu G: The uncertainty effect: When a risky prospect is valued less than its worst possible outcome. The Quarterly Journal of Economics, 2006, 121:12-83-1309. 
11. Greene JD, Morelli SA, Lowenberg K, Nystrom LE, Cohen JD: Cognitive load selectively interferes with utilitarian moral judgment. Cognition, 2008, 3:1144-54.

12. Kahane G, Everett JA, Earp BD, Caviola L, Faber NS, Crockett MJ, Savulescu J: (2017). Beyond sacrificial harm: A two-dimensional model of utilitarian psychology. Psychological Review. 2017, 2:131-64.

13. Keysar B: Communication and miscommunication: The role of egocentric processes. Intercultural Pragmatics. 2000, 1: 71-84.

14. Kohlberg L: Stages of moral development. Moral education, 1971, 51:23-92.

15.* Kouchaki M, Smith IH, Savani K: Does deciding among morally relevant options feel like making a choice? How morality constrains people's sense of choice. Journal of personality and social psychology. 2018, 5:788-804

An empirical article that demonstrates people experience a lower sense of choice when they are deciding between morally relevant options than when they perceive the options to be morally irrelevant.

16. Kruger J, Epley N, Parker J, Ng ZW: Egocentrism over e-mail: Can we communicate as well as we think?. Journal of personality and social psychology. 2005, 6:925-36.

17.* Kumar A, Epley N: Undervaluing Gratitude: Expressers Misunderstand the Consequences of Showing Appreciation. Psychological science. 2018, 29(9), 14231435.

An empirical article showing that people systematically undervalue the positive impact of expressing gratitude due to egocentric biases.

18. LaFollette H, Graham G: Honesty and intimacy. Journal of Social and Personal Relationships. 1986, 1:3-18.

19. Larrick ER, Wu G: Claiming a large slice of a small pie: Asymmetric disconfirmation in negotiation. Journal of Personality and Social Psychology. 2007, 2:212-33.

20.** Levine EE, Cohen TR: You can handle the truth: Mispredicting the consequences of honest communication. Journal of Experimental Psychology: General. 2018, 9:1400-29. An empirical article examining the predicted and actual consequences of honest and benevolent communication.

21. Levine EE, Schweitzer ME: Are liars ethical? On the tension between benevolence and honesty. Journal of Experimental Social Psychology. 2014, 53:107-17.

22. Levine EE, Schweitzer ME: Prosocial lies: When deception breeds trust. Organizational Behavior and Human Decision Processes. 2015, 126:88-106. 
23.** Levine EE, Hart J, Moore K, Rubin E, Yadav K, Halpern S: The surprising costs of silence: Asymmetric preferences for prosocial lies of commission and omission. Journal of Personality and Social Psychology. 2018, 1:29-51.

An empirical article that demonstrates communicators and targets make asymmetric judgments of prosocial lies of commission and omission due to egocentric biases.

24. Levine, EE. (2015). Lie to others as you would have others lie unto you: community standards of deception. In Academy of Management Proceedings (Vol. 2015, No. 1, p. 10533). Briarcliff Manor, NY 10510: Academy of Management.

25. Loewenstein G, Schkade D: Wouldn't it be nice?: Predicting future feelings. In Wellbeing: The foundations of hedonic psychology. Edited by Kahneman D, Diener E, Schwartz N. Russell Sage Foundation; 1999: 85-105.

26.** Lupoli MJ, Jampol L, Oveis C: Lying because we care: Compassion increases prosocial lying. Journal of Experimental Psychology: General, 2017, 7: 1026-42.

An empirical article showing that compassion increases the use of prosocial lies.

27.* Lupoli MJ, Levine EE, Greenberg AE: Paternalistic lies. Organizational Behavior and Human Decision Processes. 2018, 146:31-50.

An empirical article exploring the negative reactions to paternalistic lies.

28. Molinsky A, Margolis $\mathrm{J}$ : Necessary evils and interpersonal sensitivity in organizations. Academy of Management Review. 2005, 2:245-68.

29. Margolis J, Molinsky A: Navigating the bind of necessary evils: Psychological engagement and the production of interpersonally sensitive behavior. Academy of Management Journal. 2008, 5:847-72.

30. Mayer RC, Davis JH, Schoorman FD: An integrative model of organizational trust. Academy of management review. 1995, 3:709-34.

31. Mazar N, Amir O, Ariely D: The dishonesty of honest people: A theory of self-concept maintenance. Journal of marketing research. 2008, 6:633-44.

32. Moore AK, Munguia Gomez D, Levine EE: Everyday dilemmas: New directions on the judgment and resolution of benevolence-integrity dilemmas. Unpublished theory.

33. O’Donoghue T, Rabin, M: Doing it now or later. American Economic Review, 1999, 89:103-24.

34. Pruitt DG, Rubin JZ (Eds): Social conflict: Escalation, impasse, and resolution. Addision-Wesley; 1986.

35. Ritov I, Baron J: Reluctance to vaccinate: Omission bias and ambiguity. Journal of Behavioral Decision Making, 1990, 4:263-77. 
36. Ritov I, Baron J: Outcome knowledge, regret, and omission bias. Organizational Behavior and Human Decision Processes. 1995, 2:119-27.

37. Rogers T, Norton MI: The artful dodger: Answering the wrong question the right way. Journal of Experimental Psychology: Applied. 2011, 2:139-47.

38.** Rogers T, Zeckhauser R, Gino F, Norton MI, Schweitzer ME: Artful paltering: The risks and rewards of using truthful statements to mislead others. Journal of Personality and Social Psychology. 2017, 3:456-73.

An empirical article exploring the interpersonal consequences of paltering, which is the active use of truthful statements to convey a false impression.

39. Rosen $\mathrm{S}$, Tesser A: On reluctance to communicate undesirable information: The MUM effect. Sociometry. 1970, 253-263.

40. Ross M, Sicoly F: Egocentric biases in availability and attribution. Journal of personality and social psychology. 1979, 3:322-36.

41. Savitsky K, Keysar B, Epley N, Carter T, Swanson A: The closeness-communication bias: Increased egocentrism among friends versus strangers. Journal of Experimental Social Psychology, 2011, 1:269-73.

42.* Steinmetz, J., Sezer O, Sedikides C: Impression mismanagement: People as inept selfpresenters. Social and Personality Psychology Compass. 2017, 6:12321.

A theoretical review article that argues people are inept self-presenters due to failed perspective taking and narcissism.

43. Tesser A, Rosen S: The reluctance to transmit bad news. In Advances in experimental social psychology. Edited by Academic Press; 1975:193-232.

44. Wilson TD, Wheatley T, Meyers JM, Gilbert DT, Axsom D: Focalism: A source of durability bias in affective forecasting. Journal of Personality and Social Psychology, 2000, 78: 821-36.

45. Yeager DS, Purdie-Vaughns V, Garcia J, Apfel N, Brzustoski P, Master A, Hessert WT, Williams ME, Cohen GL: Breaking the cycle of mistrust: Wise interventions to provide critical feedback across the racial divide. Journal of Experimental Psychology: General, 2014, 2: 804-24.

46. Zhang Y, Epley N: Exaggerated, mispredicted, and misplaced: When "it's the thought that counts" in gift exchanges. Journal of Experimental Psychology: General. 2012, 4:667-81.

47.** Zhang T, Gino F, Margolis J: Does Could Lead to Good? On the Road to Moral Insight. Academy of Management Journal. 2018, 3:857-95 
An empirical article exploring moral insight - an alternative solution to competing moral imperatives.

48. Zhao X, Epley N: Why hold back that compliment? People underestimate the positive impact of compliments on recipients. Unpublished results. 